\title{
Environmental Stress in Military Settings
}

\author{
Wendy Sullivan-Kwantes, Matthew Cramer, Fethi Bouak, and \\ Leonard Goodman
}

\section{Contents}

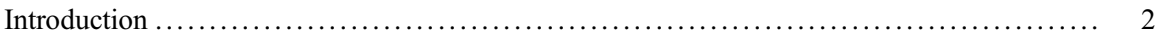

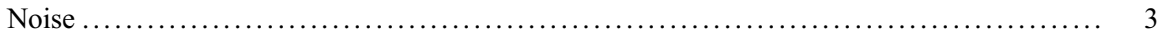

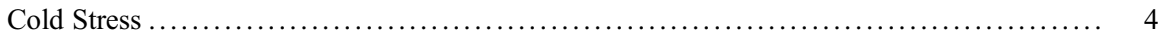

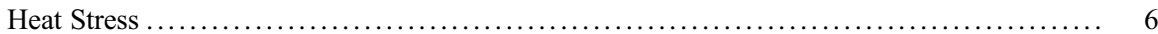

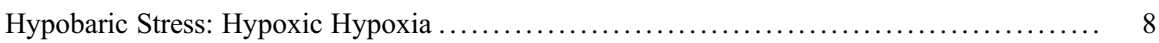

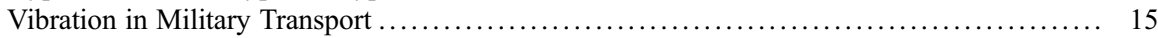

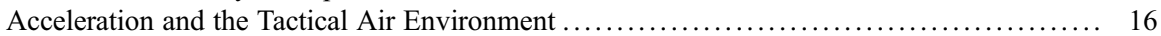

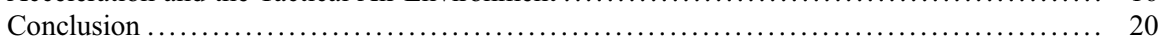

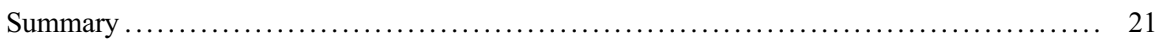

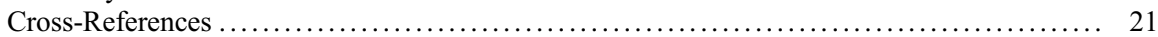

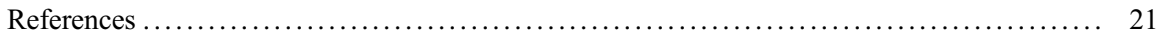

\section{Abstract}

During military training and operations, exposure to extremes of noise, temperature, humidity, pressure, or acceleration can induce levels of physiological strain that degrade cognitive and physical capabilities, threaten health and safety, and affect behavior and performance. The overarching purpose of this chapter is to discuss the impact of environmental stress on military personnel. Because each of the aforementioned stressors induces disparate effects, each section addresses a unique stressor in terms of (i) the nature of the threat, (ii) physiological and biomedical effects, (iii) the impact on performance, and (iv) management strategies. The evolution of next-generation wearable biosensors, smart performance algorithms, and scientifically based operational training methods including stress

\footnotetext{
W. Sullivan-Kwantes $(\bowtie) \cdot$ M. Cramer $\cdot$ F. Bouak $\cdot$ L. Goodman Defence Research and Development Canada, Toronto Research Centre, Toronto, ON, Canada e-mail: Wendy.sullivan-kwantes@ecn.forces.gc.ca; Wendy.Sullivan-Kwantes@drdc-rddc.gc.ca; Matthew.Cramer@ecn.forces.gc.ca; Matthew.Cramer@drdc-rddc.gc.ca;

Fethi.Bouak@ecn.forces.gc.ca; Fethi.Bouak@drdc-rddc.gc.ca;

Leonard.goodman@ecn.forces.gc.ca; Len.Goodman@drdc-rddc.gc.ca
} 
inoculation exposure that will contribute to improved training, adaptation, and tolerance to these operational stresses is discussed.

\section{Keywords}

Stress $\cdot$ Behavior $\cdot$ Cold $\cdot$ Heat $\cdot$ Noise $\cdot$ Hypoxia $\cdot$ Acceleration $\cdot$ Human performance $\cdot$ Cognitive

\section{Introduction}

Wars are fraught with action, turmoil, danger, and unpredictable situations, all of which cause varying types and levels of stress that can impact warfighters' performance. Stress can be described as a measurable physical, biological, or cognitive response to a stressor - a stimulus or event that is perceived as a threat, which results in a response that affects the human's physical or cognitive performance and wellbeing (Lloyd and Havenith 2016; Kavanagh 2005). If the stress continues over an extended period, it can result in long-term physical and/or mental injuries (Lloyd and Havenith 2016; Kavanagh 2005).

Stress can impact how humans behave. Depending on the nature of the stress, behavior can be affected in either positive or maladaptive ways and can be immediate or delayed, compromising future tasks (Tiwari 2011). How behavior is affected depends on several factors including one's personality, personal experiences, and training. Training (as we discuss later in this chapter) is one way to positively influence the behavioral responses to a variety of stresses and is extremely important in the military context.

While this chapter focuses on environmental stressors, it is worth mentioning that other common stressors, such as psychological (e.g., past trauma (Tiwari 2011)), biological (e.g., fatigue), social (e.g., interpersonal conflicts (Lazarus and Cohen 1977)), and cognitive stressors (e.g., mental load (Tiwari 2011)) have the potential to negatively affect performance. Such stressors can happen in conjunction with environmental stressors and may have an additive effect on stress experienced by a person. The full understanding of the impact of multiple physical and cognitive environmental stressors is still being developed (Lloyd and Havenith 2016; Tiwari 2011) because it is not always clear how the factors will interact or if they tend to be additive in nature. These stressors can also have emotional and/or behavioral consequences in common that impact human performance. In sum, external environmental stressors can impact performance differently and the resulting effect on human performance can be more serious when combined with other, non-environmental stressors.

Environmental stressors include a variety of physical stimuli, including noise, temperature (heat and cold), pressure (hypobaric [altitude] and hyperbaric [underwater]), $24 \mathrm{~h}$ darkness or light, and vibration that can alter a person's ability to function or survive. It is important to note that stress can sometimes be beneficial to human performance, and some research reports performance can be positively 
correlated with stress to a point; however, after that point, performance starts to suffer (Tiwari 2011). Moderate levels of stress have been argued to increase performance by providing just enough stimulation to encourage alertness, individual effort, and motivation whereas too much or too little stress can be associated with decreases in performance (Kavanagh 2005). How stress affects behavior is not limited to the individual - stress affects group behavior too. Stress can be a negative influence on how groups function, something important to consider in a military context where group work is common (Kavanagh 2005).

Below we will briefly introduce several environmental stressors typically experienced by military personnel and the impact that these stressors have on human performance. Each section addresses a unique military stressor in terms of (i) nature of the threat, (ii) physiological and biological effects, (iii) the impact of these stressors on performance, and (iv) management strategies.

\section{Noise}

Although knowledge of noise as an environmental stressor can be traced back for centuries, it is only in the past few hundred years that population growth and industrialization has drawn attention to the true impact that noise has on health and well-being (Münzel et al. 2018). In addition to the regular ambient noise to which people are exposed like traffic, airports, restaurants, and other public spaces, military personnel are exposed to noise in a variety of job-relevant tasks and environments during training or deployment. Military personnel may also be exposed to more intense sounds than any other occupation (Jokel et al. 2019).

Whether it is the sound of a large aircraft engine, naval ship, command center chatter, bullets, or explosives, noise from military environments, many of which exceed noise standard limits (Jokel et al. 2019), can impair sleep, communication, vigilance, learning, and can be harmful to health (Goines and Hagler 2007). There are several types of noise that can cause stress to military personnel. Impulse noise refers to an exposure to explosions or weapons fire, including small firearms such as rifles and shotguns. Other firearms (like machine guns), engines, vehicles, or aircraft create what is referred to as steady-state noise (Nakashima and Farinaccio 2015). Impulse noise can cause potentially permanent hearing damage with one or few exposures, whereas the damaging effects of steady-state noise on hearing can occur as a result of long-term exposure (Nakashima and Farinaccio 2015; Keller et al. 2017).

The stress caused by excessive noise can result in several issues of varying impact depending on the situation. Excessive noise can hinder everyday communication because of degraded speech comprehension and signal distortion causing communication delays and missed messages or orders. Excessive noise can also have negative impacts on cognitive ability by disrupting concentration and causing an overall reduction in one's ability to sustain attention (Jokel et al. 2019). There are also non-speech related auditory consequences such as an impaired ability to locate sounds during combat (Nakashima and Farinaccio 2015). Finally, long-term 
exposure to excessive noise can cause permanent hearing loss and tinnitus (Jokel et al. 2019; Nakashima and Farinaccio 2015; Keller et al. 2017).

Hearing loss in the military population is the second-most prevalent service-related injury (Yong and Wang 2015). As a potentially preventable injury, prevention efforts through adequate hearing protection and modifications for quieter workspaces will not only improve communication performance during operations or training, and help ensure awareness for environmental cues such as weapon fire, alarms, and other important communications, but will help to retain personnel and prolong the careers of highly trained military personnel (Nakashima and Farinaccio 2015).

Behavior modification is common under environmental noise situations where soldiers will have to change how they conduct their work, for example, by making requests for clarifications and repeated messages to accomplish their tasks (Jokel et al. 2019). Similar behavior modifications to other environmental stressors can be helpful or potentially harmful by leading to unwanted consequences. For example, depending on the situation, wearing hearing protection could impede situational awareness for soldiers in the field by limiting their ability to communicate or to hear external threats such as the proximity and direction of enemy fire (Keller et al. 2017).

\section{Cold Stress}

Cold weather injuries, including hypothermia and frostbite, have been an environmental cause of stress to military operations for centuries. During World Wars I and II and the Korean War, for example, thousands of soldiers suffered from cold weather injuries and even death due to the cold (Candler 1997). More recently, cold weather injuries have been sustained by US and Canadian troops during training exercises in cold climates (Candler 1997; Sullivan-Kwantes et al. 2017). Such injuries can result in the loss of personnel available for missions and can cause long-term, life-altering injuries like amputations or, in some cases, death.

Cold weather injuries can occur when tasks are performed under conditions of cold air, rain, wind, or water immersion. Excessive cooling can lead to impaired manual performance. With extreme cold exposure, a decrease in core temperatures can result in hypothermia (a core temperature below $35^{\circ} \mathrm{C}$ ), symptoms and consequences of which are shown in Table 1.

The class of injuries referred to as freezing cold injuries include frostnip and frostbite. Frostnip is a mild cold-weather injury characterized by superficial freezing of the skin that results in numbness but no permanent damage. Research does indicate, however, that one's susceptibility to frostnip may increase the risk for frostbite (Gorjanc et al. 2019). Frostbite occurs when tissue reaches approximately $-0.55{ }^{\circ} \mathrm{C}$ but can occur at even higher skin temperatures depending on how long the tissue is exposed to cold (Handford et al. 2014). Early signs of frostbite are pain and numbness, a white and waxy appearance, and a hard "wooden" texture.

A non-freezing cold injury occurs with sustained exposure to cold and wet conditions for several hours or days. Non-freezing cold injuries can involve numbness, swelling, pain, and sensory issues (Vale et al. 2017). Historically, chilblains 
Table 1 Core temperature and associated symptoms during cold stress (Department of the Army 2005)

\begin{tabular}{l|l|l}
\hline \multirow{2}{*}{$\begin{array}{l}\text { Core Temperature } \\
\left({ }^{\circ} \mathrm{C}\right)\end{array}$} & Symptoms \\
\hline Normothermia & 37.0 & \\
\hline \multirow{4}{*}{$\begin{array}{l}\text { Moderate } \\
\text { hypothermia }\end{array}$} & 35.0 & Maximal shivering; elevated blood pressure \\
\cline { 2 - 3 } & 34.0 & Amnesia, dysarthria; poor judgment \\
\cline { 2 - 3 } & 33.0 & Ataxia; apathy \\
\cline { 2 - 3 } & 32.0 & Stupor \\
\hline & 31.0 & Shivering ceases; pupils dilate \\
\hline \multirow{5}{*}{$\begin{array}{l}\text { Severe } \\
\text { hypothermia }\end{array}$} & Cardiac arrhythmias; reduced cardiac output \\
\hline & 28.0 & Unconsciousness \\
\cline { 2 - 3 } & 27.0 & Ventricular fibrillation likely; hypoventilation \\
\hline & 26.0 & Loss of reflexes and voluntary movement \\
\cline { 2 - 3 } & 25.0 & Acid-base disturbances; no response to pain \\
\cline { 2 - 3 } & 24.0 & Reduced cerebral blood flow \\
\cline { 2 - 3 } & 23.0 & Hypotension; bradycardia; pulmonary edema \\
\cline { 2 - 3 } & 19.0 & No corneal reflexes; areflexia \\
\cline { 2 - 3 } & 18.0 & Electroencephalographic silence \\
\cline { 2 - 3 } & 16.0 & Asystole \\
\hline
\end{tabular}

(perniosis) and trenchfoot have been the main non-freezing cold injuries affecting military personnel (Vale et al. 2017) and are still a concern because they significantly impact human performance and, in some cases, employability in the military. Surprisingly, clear diagnostic criteria for non-freezing cold injuries are still being debated by subject matter experts (Vale et al. 2017).

One of the major human performance concerns when operating in the cold is the loss of manual dexterity, which declines precipitously once hand and finger temperatures fall below $\sim 15{ }^{\circ} \mathrm{C}$ (Schiefer et al. 1984), causing the largest effect on tasks requiring fine finger dexterity (Castellani et al. 2018). From an operational perspective, having cold fingers may negatively impact the activities required to keep a mission on track (like equipment repairs or medical procedures) and one's ability to handle weapons.

It is unclear from current research how cold stress affects cognitive performance (memory, reaction time, vigilance, and attention) for military personnel - possibly because the operational definition of "cold" can differ across studies. Some studies have found little to no difference in cognitive performance in cool (not cold) environments (Martin et al. 2019). Other research has reported both improvements and impairments to cognitive performance in the cold (Martin et al. 2019). Military task performance, such as target detection, has not been shown to be negatively impacted by the cold (Martin et al. 2019). Cold can introduce psychological challenges that impair human performance. As noted by Nindl et al. (2018), a military member's psychological resilience, combined with their level of training, experience, physiological fitness, behavior, equipment, and effectiveness of leadership, 
affect the ability to cope with operational stress. Success for the military means not only surviving but adapting to the cold to retain effectiveness.

There are several interventions that may help to combat cold stress. Behavioral responses to increase body heating are the most common (increasing physical activity or building a fire) and/or reduce body heat loss, (adding more protective clothing or seeking shelter). There is some evidence to suggest that supplements, such as tyrosine and caffeine, may help combat the negative effects of cold on cognitive performance (Taylor et al. 2016). However, when considering the impact of cold on cognitive performance during military operations, one must consider other factors, such as sleep deprivation, dehydration, and nutrition (due to an inability to prepare food properly), which may compound the impairment. Therefore, our understanding of the effect of cold on cognitive performance for military personnel needs to be understood in the context in which it occurs.

Prevention of cold-weather injuries involves risk management planning to assess potential cold-weather risks to health and performance and to implement the necessary controls. Factors requiring consideration include individual levels of risk, nutrition, hydration, clothing, physical activity, monitoring, and cold-mitigation strategies. Some evidence suggests that practicing cold-water immersion may reduce anxiety, pain, and delay the onset of shivering (Cheung 2015). For these reasons, cold acclimation has been proposed as a training tool to improve human performance, reduce cold-weather injuries, and improve cold tolerance (Gordon et al. 2019; Jones et al. 2017). Whether cold acclimation can be effectively implemented and maintained in military personnel requires further investigation. Other prevention measures aim to mitigate body cooling. Strategies center on the behavioral responses listed above, as well as keeping clothing dry. Skin-heating devices increase peripheral blood flow and slow the decline in skin temperature (Castellani et al. 2018) but have not been widely implemented in the field.

Military leaders and medical personnel should monitor troops for signs of cold injury because they tend to be underreported (Sullivan-Kwantes et al. 2017). Proper reporting is crucial to ensuring appropriate treatment so that soldiers can recover and minimize the risk of future cold injury. Prevention of freezing cold injuries for military personnel is important for maintaining current and future cold operations because, depending on the degree of injury, the solider may have to be removed from the field, an operation, or the military. Once a person sustains a freezing cold injury, they can experience continued hypersensitivity to the cold and be at an elevated risk for another such injury, which can affect their performance on future cold operations (Gorjanc et al. 2019).

\section{Heat Stress}

That heat exposure can be debilitating or lethal, and thereby impact battlefield success, has been recognized by military commanders for millennia (Jarcho 1967; Olsen 1997; Goldman 2001). The scientific study of heat effects on military personnel began during British and European colonialism, as heat became a major source of illness among 
troops stationed in tropical and desert climates (Bricknell 1995). Since then, military forces have devoted considerable effort toward understanding and expanding soldiers' tolerance to heat stress, with the goal of maximizing effectiveness and minimizing heat casualty risk (Ashworth et al. 2020; Nye and O'Connor 2020).

Detrimental effects of heat exposure are largely mediated by excessive elevations in body temperature. Normally, humans maintain a relatively stable body temperature by balancing body heat production from metabolism with an equivalent amount of heat loss. Heat stress tips this balance such that heat production exceeds heat loss, causing body temperature to rise. This occurs with physical exertion and/or if heat loss is limited by environmental factors (high air temperature, thermal radiation, humidity) and clothing.

Military working conditions often create heat stress. High temperatures and humidity levels can be expected during training exercises or deployments conducted in tropical or dry climate systems, or during summer months in temperate and continental climates. Rapid deployment to such conditions can be particularly problematic without the benefit of prior heat acclimatization. Similarly, divers performing tasks in desert climates may encounter very warm shallow-water temperatures. Vehicles, vessels, and aircraft can also be a major source of environmental heat stress (Kozlowski 2009). High temperatures in armored vehicles and seacraft can produce extremely high humidity levels as evaporated sweat from personnel causes moisture to accumulate inside crew compartments (Schlader et al. 2015; Jacobs et al. 2007). Thermal radiation from avionics, proximity to jet engines, and sun exposure through aircraft canopies can greatly elevate cockpit temperatures (Kenefick et al. 2008). Training and operational tasks can be physically demanding. Rapid movement speed, sometimes under heavy load, may be required during marches, patrols, and reconnaissance, especially during high-tempo operations. Personal protective clothing and equipment, such as body armor, flight ensembles (G-suits, immersion protection), and chemical, biological, radiological, nuclear, and explosive (CBRNE) defense, can be heavy, cumbersome, and impede body heat loss.

The human response to heat stress involves directing more blood flow to the skin and increasing sweat production, which together promote heat loss. Although these responses can effectively control body temperature, large and sustained elevations in skin blood flow and sweat rate can induce considerable strain on the body. Redistribution of blood to the skin, coupled with sweat-induced dehydration, limits the amount of blood returning to the heart, threatening its ability to maintain blood flow to the brain and other vital organs. For this reason, the ability to manage other stressors that threaten blood flow to the brain, such as prolonged standing (e.g., sentry duty), acceleration (e.g., tactical aviation), and hemorrhage, is seriously impaired by the addition of heat stress (Nunneley and Stribley 1979; Crandall et al. 2019). With combined exercise and environmental heat stress, the body's capacity for heat loss may be overwhelmed, causing body temperature to rise persistently until a serious heat illness occurs. The most common is heat exhaustion, characterized by an inability to continue physical activity due to extreme cardiovascular strain and dehydration. The most severe heat illness, heatstroke, is defined by extremely high body temperatures and impaired mental status. Heatstroke requires immediate and aggressive cooling to avoid organ/tissue damage and death. Serious 
heat illness has an immediate impact on operational effectiveness and the consumption of medical resources. Recovery (often several weeks) following heatstroke contributes to lost duty time that may impact unit readiness. Additionally, prior heat illness can increase the likelihood of a future episode of heat illness, which must be considered before future operations.

Body heat strain can degrade mental, psychomotor, and physical task performance. Mental tasks requiring vigilance are the most susceptible to heat, especially those perceived to be boring. This is particularly problematic due to the importance of vigilance in military operations (e.g., patrol, sentry duty, vehicle operations). Prolonged heat stress impairs complex mental tasks requiring memory, interpreting information, and reasoning. In contrast, simple reaction time tasks, such as target detection, are largely unaffected by heat. Prolonged heat exposure also degrades manual coordination and steadiness, which can affect marksmanship. Heat-related deteriorations in steadiness and attention affect tracking ability, which is required for piloting, target acquisition, and weapons alignment. Additionally, with sustained physical work (e.g., march, patrol) in conditions that restrict sweat evaporation (e.g., high humidity, little airflow, and/or protective clothing), rapid elevations in body temperature and cardiovascular strain limit work time. The relationship between work intensity and maximum work time during heat exposure while wearing CBRNE protection is demonstrated in Fig. 1 (McLellan et al. 2013).

Within a unit, the risk of heat-related illness and degradations in performance may not be equal between soldiers. This is because the physiological responses to a given level of heat stress are highly variable between individuals. Numerous factors contribute to this variability; the most common are summarized in Table 2. Commanders and medical officers must be aware of these risk factors to properly manage heat casualty risk.

Heat stress management is critical for preventing heat casualties. Most importantly, leadership must fully inform personnel of the risk associated with heat stress. Heat acclimatization and adequate water intake are key for optimizing effectiveness. Adherence to prescribed work/rest cycles based on environment, work intensity, and clothing can effectively limit the cumulative amount of heat stress and prevent dangerous heat strain. Similarly, mission planning algorithms use physical activity factors (speed, load, slope, terrain), individual traits (body size, acclimatization, hydration), environmental parameters, and clothing properties to predict physiological strain, and prescribe work/rest balance and water needs. Direct cooling can also assist in heat management (McLellan et al. 2013). Examples include liquid or air circulation underneath protective clothing, ice vests, or water immersion; though the method used must account for the soldier's requirements for mobility, strain of added mass, power requirements, and integration with protective ensembles.

\section{Hypobaric Stress: Hypoxic Hypoxia}

Military aviators flying at high altitude and soldiers traversing mountainous terrain are exposed to low atmospheric pressures. The ensuing stress generates a variety of physical, physiological, and psychological responses on humans, who are not 


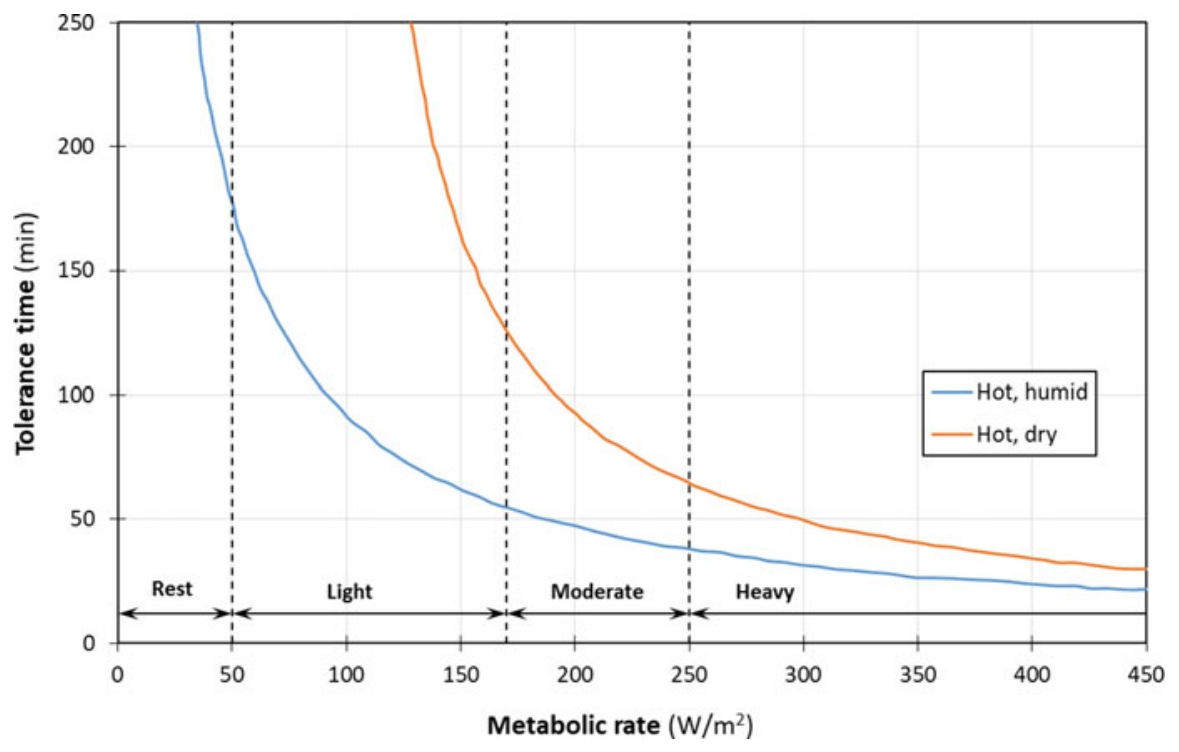

Fig. 1 Relationship between work tolerance time and metabolic rate while wearing the Canadian Forces nuclear, biological, and chemical protective clothing ensemble in hot-dry and hot-humid environmental conditions. Dotted vertical lines demarcate metabolic rates consistent with the indicated work intensities. Reproduced with permission from the Canadian Department of National Defence. The source is Defence R\&D Canada

adapted to function in such a hostile environment. The effects could be profound on performance and may cause serious risks that could result in injuries or fatalities, impacting mission success. Historically, the effects of altitude began to be understood in the sixteenth century (Houston 1987; DeHart 1996). In aviation, the first detailed description of the effects of altitude can be traced back to the early balloon flights in the eighteenth century (West 1998). The first comprehensive scientific studies began in the late 1870s (Hitchcock 1971). They were the first experiments to demonstrate that specific ill effects and symptoms were the result of oxygen deficiency, that is, hypoxia, in the body and the decrease of the oxygen partial pressure $\left(\mathrm{PO}_{2}\right)$ at altitude (Bert 1878; Marotte 2006).

The inherent risk of hypoxic hypoxia during flight has been recognized for some time. It was a serious hazard in both World Wars and remains a potential danger in the present, with recent events of in-flight hypoxia-induced symptoms in modern military aircraft, which can fly longer at increased operational altitudes. For example, the number of hypoxia episodes within the US Navy F/A-18 community increased tenfold between 2010 and 2017 (Rice et al. 2019). Because in-flight hypoxia incidents can result in total loss of precious life and costly aircraft, understanding the impairments and recognizing the symptoms is of paramount importance for aircrew operating at altitude. In practice, hypoxia arises from (i) breathing air at high altitude in an unpressurized aircraft, (ii) a loss of cabin pressure in a pressurized aircraft, (iii) failure or absence of an on-board life support systems, or (iv) incorrect use of the oxygen equipment. 
Table 2 Risk factors for exertional heat illness (EHI) among military personnel

\begin{tabular}{|c|c|}
\hline Risk factor & Consequences \\
\hline \multicolumn{2}{|l|}{ Individual factors } \\
\hline Low aerobic capacity & $\begin{array}{l}\text { Aerobic fitness improves evaporative capacity and lowers } \\
\text { cardiovascular strain }\end{array}$ \\
\hline $\begin{array}{l}\text { Lack of heat } \\
\text { acclimatization }\end{array}$ & $\begin{array}{l}\text { Heat acclimatization maximizes evaporative capacity and lowers } \\
\text { cardiovascular strain }\end{array}$ \\
\hline Motivation & $\begin{array}{l}\text { Desire or pressure to complete training can push individuals beyond } \\
\text { tolerance limits }\end{array}$ \\
\hline Dehydration & Can attenuate sweat rate, exacerbates cardiovascular strain \\
\hline \multicolumn{2}{|l|}{ Illness or injury } \\
\hline Febrile illness & Accentuates hyperthermia \\
\hline Recent viral infection & Accentuates hyperthermia, compromises immune response \\
\hline Skin grafts & Extensive grafts lower evaporative capacity in burn survivors \\
\hline \multicolumn{2}{|l|}{$\begin{array}{l}\text { Medications \& } \\
\text { Supplements }\end{array}$} \\
\hline Amphetamines & $\begin{array}{l}\text { Delay fatigue and prolong exertion; increase heat production, heart } \\
\text { rate, blood pressure }\end{array}$ \\
\hline $\begin{array}{l}\text { Anticholinergics (e.g., } \\
\text { atropine) }\end{array}$ & Impaired sweating and skin blood flow \\
\hline Antihistamines & Impaired sweating \\
\hline $\begin{array}{l}\text { Beta-blockers (e.g., } \\
\text { propranolol) }\end{array}$ & Attenuated blood pressure, skin blood flow \\
\hline Diuretics & Fluid and electrolyte depletion \\
\hline NSAID & Gut and liver toxicity \\
\hline Ephedrine & Greater heat production, heart rate, blood pressure \\
\hline \multicolumn{2}{|l|}{ Genetics } \\
\hline Sickle-cell trait & Higher EHI incidence; mechanism unclear \\
\hline RYR-1 mutation & Greater heat production (malignant hyperthermia) \\
\hline TLR4 polymorphisms & Diminished endotoxin response \\
\hline
\end{tabular}

NSAID, nonsteroidal anti-inflammatory drugs; RYR1, ryanodine receptor 1 gene; TLR4, toll-like receptor 4 gene

Hypoxia manifests as an inadequate supply of oxygen by arterial blood to tissues, resulting in rapid impairment of bodily function, especially in the central nervous system (Haldane et al. 1919). Although the oxygen concentration in the air is the same at sea-level and high altitude, the reduction in barometric pressure as humans ascend to high altitude means a lower $\mathrm{PO}_{2}$. Thus, the gradient for oxygen diffusion in the body is lower than at sea level, reducing the capacity of gas exchange between the atmosphere and the cells. Altitude-related hypoxic stress produces a combination of physiological and psychological effects on individuals, accompanied by a remarkable variety of signs and symptoms that can have serious consequences, leading to unconsciousness. Given the oxygen deficiency at altitude, effects include increased depth of breathing while the cardiovascular system tries to compensate by increasing blood flow to the tissues. Depending on the hypoxia level, heart rate increases, and cardiac output is redistributed to maintain oxygen delivery to the most critical tissues 
(i.e., brain and heart). Signs and symptoms can be grouped into five objective and subjective types: (i) general (headaches, tingling, numbness, breathing difficulty, feelings of warmth or cold); (ii) cognitive (memory, lapses, judgment, confusion), (iii) psychomotor (reaction time, communication, muscular, eye-hand coordination); (iv) behavioral (personality, mood); (v) visual (acuity, peripheral, night, color) (Haldane et al. 1919; Carson et al. 1969; Smith 2008). The degree and severity depends on altitude exposure level and duration with or without physical exertion. These symptoms can be unique to every person and, when they occur, constant throughout their life when exposed to hypoxic conditions. Given the insidious nature of hypoxia and the individual susceptibility of its symptoms, detection and corrective action can be difficult during flight.

Because of their high oxygen requirement, the central nervous system and the retina are highly sensitive and most vulnerable to hypoxia. Therefore, the first effect of hypoxia on performance is a decrement of visual and cerebral performance (Cudaback 1984). Visual degradation is generally consistent and starts occurring at around $1500 \mathrm{~m}(5000 \mathrm{ft})$. Over the years, the effect of hypoxia on cognitive performance and mental functioning has been investigated extensively (Cudaback 1984; Greene 1957; Petrassi et al. 2012). Motor and cognitive performance impairments vary from person to person and depend on the altitude level and rate of ascent. In addition to the decrements described above, hypoxia can also impair higher mental processes, complex decision making, and working memory such as the executive functions. The emergence of modern aircraft with a cognitively tasking cockpit highlights the importance of working memory due to the number of flying tasks performed simultaneously (Malle et al. 2013). Between $1525 \mathrm{~m}(5000 \mathrm{ft})$ and $4575 \mathrm{~m}(15,000 \mathrm{ft})$, performance decrements at varying hypoxia levels are less understood and difficult to quantify, possibly due to individual difference and absence of sensitivity or specificity of the multitude cognitive tests used. A comprehensive literature review demonstrated that the effects of hypoxic hypoxia on cognitive function at these altitudes extend to both elementary and higher-order cognitive functions, and decrements in cognitive tasks with great complexity are more likely for a given level of mild hypoxia (Petrassi et al. 2012).

Breathing air above $4575 \mathrm{~m}(15,000 \mathrm{ft})$ makes the aircrew unaware of any performance decrement or presence of symptoms, due to a significant loss of critical judgment and determination. Emotional state is affected, and the individual may become disinhibited and sometimes physically violent (Harding and Gradwell 1999). Above $6100 \mathrm{~m}$ (20,000 ft), cognitive performance and physical capacity drop rapidly, followed by convulsions, unconsciousness, and death without notice. The time of useful consciousness (also called time of effective performance) is the effective period from the interruption of the oxygen supply, or the start of low oxygen exposure environment, to the time when useful function is lost, and an individual is no longer capable of performing corrective and protective flying actions (Carlyle 1963). In practice, time of useful consciousness permits the aircrew to initiate corrective actions, such as descend to safer altitudes or initiate supplemental oxygen breathing. Altitude level, oxygen concentration, high ascent rate (or rapid decompression), physical exertion, and individual differences have been shown to greatly affect time of useful consciousness (Greene 1957). 
The adverse effects of hypoxia must be prevented during flight. It is commonly accepted that aircrew and passengers must breathe supplemental oxygen as a countermeasure for hypoxia using a breathing mask for cabin altitudes above $3048 \mathrm{~m}(10,000 \mathrm{ft})$. Signs and symptoms of hypoxia are consistent for the same individual whenever hypoxia is felt; however, they are perceived differently by different individuals. It is important that military aircrew become familiar with the effects of hypoxia on their own bodies to be able to take corrective actions. These can include a descent to safe altitudes in unpressurized cabins and use of supplemental oxygen. The familiarization with the signs and symptoms of hypoxia, also called indoctrination at high altitudes, is usually conducted in a controlled environment, either by reducing the barometric pressure in a hypobaric chamber or by breathing a reduced oxygen fraction breathing mixture at sea level to simulate altitude (known as normobaric altitude). The other benefit of indoctrination is to familiarize the aviator with the proper use of oxygen systems. Aviators with hypoxia familiarization have been found to respond better to in-flight hypoxic incidents.

As development of more capable tactical aircraft emerged in the early 1950s, it was realized that further emergency hypoxia life support systems would be needed to prevent severe hypoxia in the event of cabin decompressions above $7625 \mathrm{~m}$ $(25,000 \mathrm{ft})$. As capabilities increased, tactical aircraft were able to reach in excess of $18,300 \mathrm{~m}(60,000 \mathrm{ft})$. As tactical military aircraft incorporated jet propulsion and cabin pressurization, aircrew could maneuver and cruise at higher altitudes. This enabled surveillance at altitudes beyond weapon range, delivery of weapon systems at higher ceilings, and improved fuel efficiency and range due to the thinner atmosphere (and thus reduce drag). Next generation aircraft will be able to maintain cruise altitude up to $25,925 \mathrm{~m}(85,000 \mathrm{ft})$.

The ideal oxygen pressure in the lung's alveoli is around $100-103 \mathrm{mmHg}$ at sea level (where total barometric pressure is $760 \mathrm{mmHg}$ ). At a cabin decompression exposure altitude of $12,200 \mathrm{~m}(40,000 \mathrm{ft})$, the total barometric pressure is only $141 \mathrm{mmHg}$, this alveolar pressure will fall well below $40 \mathrm{mmHg}$, causing severe hypoxia (Ernsting 1966; Green 2016; Holness et al. 1980). To address this, researchers in the USA and the UK developed emergency breathing systems in the $1960 \mathrm{~s}$. For cabin altitudes of greater than $12,200 \mathrm{~m}(40,000 \mathrm{ft}), 100 \%$ oxygen breathing gas is immediately delivered to the lungs for a minimum total pulmonary pressure of $141 \mathrm{mmHg}$ (Ackles et al. 1978; Balldin 1978). As the exposure altitude increases past $12,200 \mathrm{~m}(40,000 \mathrm{ft})$, the pressure of oxygen delivered to the respiratory tract is increased, to maintain as close as possible to the $141 \mathrm{mmHg}$ level (Fig. 2). This increased pressure delivered to the lungs during emergency exposure to hypoxia above $12,200 \mathrm{~m}(40,000 \mathrm{ft})$ altitude is termed positive pressure breathing (PPB) (Ernsting 1966; Green 2016).

Modern military tactical aircraft continue to employ emergency PPB as an emergency hypoxia measure vs. adopting full pressure suits as emergency hypoxia equipment since (a) partial pressure ensembles allow egress and emergency ejection from the aircraft; (b) full pressure suits are environmentally hot, restrictive, and do not allow the aircrew to flex and rotate the head and trunk, which is critical to keeping situational awareness and vision in the dynamic tactical cockpit; (c) PPB 


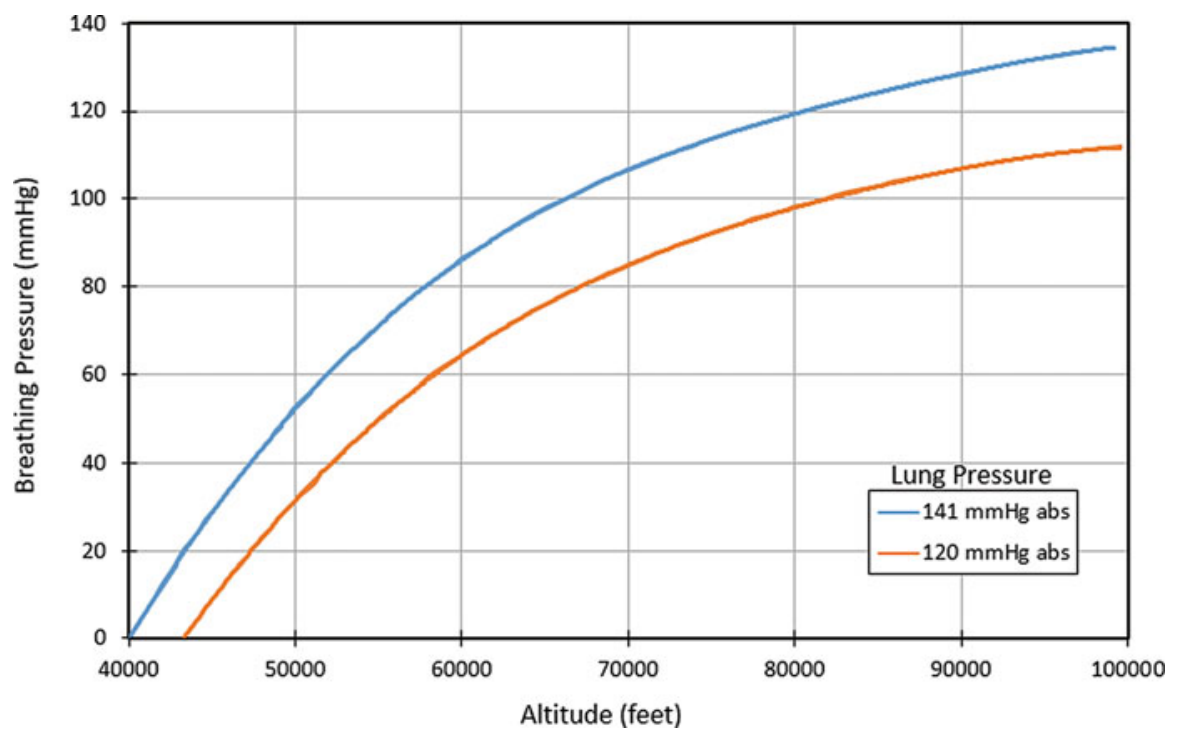

Fig. 2 As emergency cabin decompression altitude exposure increases past 12,200 m (40,000 ft), the levels of $100 \% \mathrm{O}_{2}$ pressure delivered the lungs must increase in order to maintain a minimum of $140 \mathrm{mmHg}$, ensuring at least a nominal level of alveolar oxygen pressure. This type of emergency $\mathrm{O}_{2}$ pressure delivery is termed "positive pressure breathing" or PPB. Redrawn from (Ernsting 1966). Reproduced with permission from the Canadian Department of National Defence. The source is Defence R\&D Canada

ensembles allow a modular approach and pneumatic counterpressure of the legs and thorax (via the use of the anti $G$ suit and chest counterpressure vest - discussed in more detail below) (Ackles et al. 1978; Ernsting et al. 1960) (Fig. 3).

PPB though effective in maintaining a minimum cerebral oxygenation up to very high cabin altitudes during decompression (termed "get-me-down" protection), PPB at levels above $50 \mathrm{mmHg}$ places significant strain upon the respiratory and cardiovascular systems (Ackles et al. 1978; Balldin 1978). When high-pressure gas enters the respiratory system, it must be counterbalanced across the chest wall, otherwise the alveoli may rupture, which may cause a serious air embolism. To prevent this, the gas entering the respiratory system from the emergency-breathing regulator during decompression also fills a pneumatic counterpressure vest, mitigating most of the lung distension (Ernsting 1966).

At the same time, cardiovascular function impairment also occurs when a pilot is exposed to high levels of PPB for even several seconds. As intrapulmonary pressure rises rapidly, venous return of blood back to the heart is interrupted. If PPB continues, and cardiovascular dysfunction is not addressed symptoms of syncope (including dizziness, confusion, cognitive decrements and alterations in vision) followed by loss of consciousness may ensue. Thus, paradoxically, although severe hypoxia may be corrected, there is a risk of aircrew loss of consciousness due to secondary complications of PPB (Ernsting 1966; Green 2016; Holness et al. 1980; Ackles et al. 1978; Balldin 1978). 


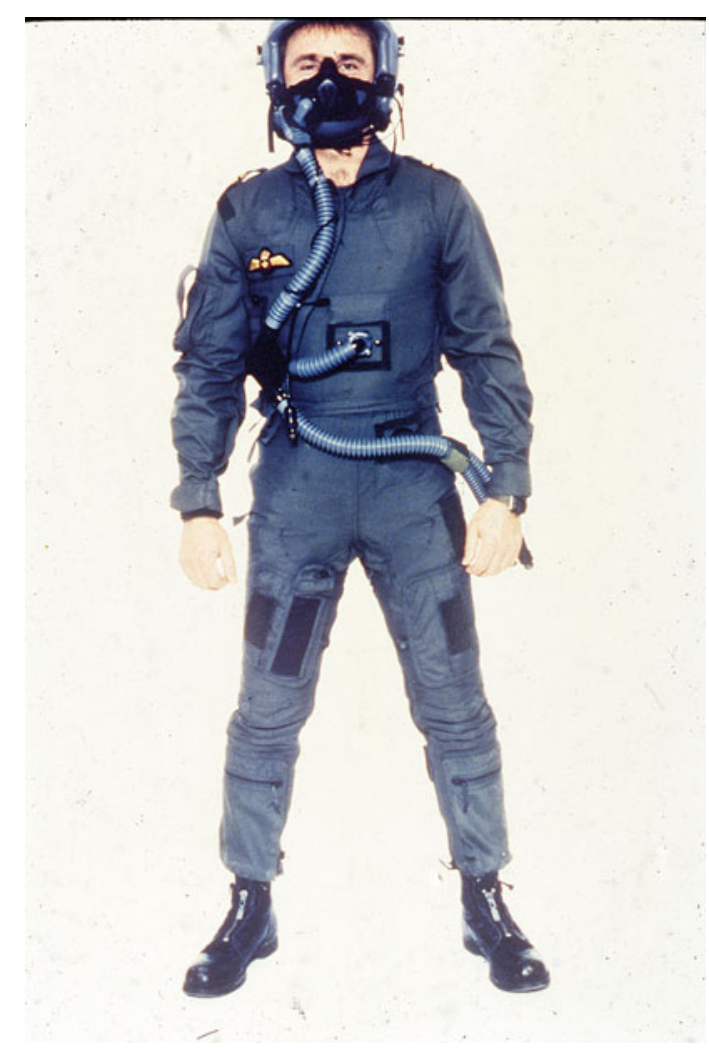

Fig. 3 Representative Positive Pressure Breathing Ensemble. Picture shows the helmet/oronasal mask, thoracic jerkin, anti-G suit, and connectors/tubing. The breathing system is tied into the aircraft's life support breathing supply and regulator (blend of bottled $\mathrm{O}_{2}$ and engine bleed air). Reproduced with permission from the Canadian Department of National Defence. The source is Defence R\&D Canada

To address these cardiovascular effects of PPB, the anti-G suit - also utilized for acceleration protection - effectively counter these effects, and restore venous return to the heart during PPB. Studies determined that the optimal protection was afforded by inflating the Anti-G suit to multiples of the breathing pressure (i.e., for $60 \mathrm{mmHg}$ oxygen delivered to the lungs, $60 \mathrm{mmHg}$ pressure inflates the torso jerkin and upwards of $4 \mathrm{x}$ the breathing pressure for the G-suit - $240 \mathrm{mmHg}$ ) (Ackles et al. 1978; Balldin 1978; Ernsting et al. 1960). Also, the increased coverage of the G-suit was directly correlated with further reductions in cardiovascular symptoms of PPB (Goodman et al. 1993).

Hypoxia may have significant impacts upon behavioral changes, especially in the very short term, as reduced cerebral oxygen levels manifest as confusion, memory deficits, and even mood alterations. These become significant when operational decision making and communication is impacted during a sudden life support 
system failure, and when emergency procedures need to be enacted immediately. On the other hand, there is very little evidence that exposure to an acute bout of severe hypoxia during a cabin decompression leads to significant long-term behavioral or cognitive effects or any permanent structural changes to the central nervous system.

Aircrew training for high altitude emergency hypoxia typically involves a combination of in-class instruction (theory and physiology of high-altitude hypoxia and countermeasures, severe hypoxia recognition), followed by direct exposure/simulation of high levels of PPB at ground-level. This is accomplished by using custom air delivery systems which deliver high pressure air to the lungs, and the full PPB ensemble. Occasionally, PPB training is also combined with simulated emergency scenarios, which provide additional cognitive challenges to encourage further habituation and training opportunities for aircrew. This enables indoctrination of the sensations of high levels of PPB and allows habituation in a safe environment.

\section{Vibration in Military Transport}

Vibration is defined as a series of impulses transmitted to the body. These may be directed to the body through direct contact with a vibrating object/structure or transmitted through the air as sound waves. In essence, vibrations at many common frequencies are perceived as sound by the human auditory system, whereas at low frequencies, impulses arriving at the body are felt physically. At one end of the vibration spectrum are explosion/blast and firearms discharges that produce high magnitude vibration effects, which are the most destructive to the human (organs, skeletal, muscular, soft tissue, and brain), or on the other spectrum ultra-high frequency vibrations/acoustics, which may have large negative effects on hearing perception and communication. However, for the purposes of this section, we summarize the effects of lower-range $(60-100 \mathrm{~Hz})$ non-weapon and non-acoustic related vibrations upon the soldier (Coerman 1940).

Vibration is commonly experienced in many military operating environments, and these range from undersea (e.g., vibrations emanating from self-contained breathing apparatus) and inside over-land vehicles (buffet, rough terrain, and drive-train effects), but most commonly in the aerospace environment. Helicopter rotor rotations and air turbulence vibration during high speed/high acceleration flight in tactical aircraft account for most of the vibration effects encountered (Griffin 1990; Guignard and King 1972).

Helicopter-induced vibration causes the greatest impact upon aircrew performance (auditory, visual disturbances) and health. In particular, the effect of these low-frequency rotor-caused vibrations manifests in neck and back soft-tissue and skeletal pathology and pain. When combined with unnatural postures, which are used in many operations, and the wearing of heavy helmet/head-up night vision equipment, the incidence of debilitating neck pain is significant. Although only one contributor to helicopter neck pain, active Aviation Medicine research continues, with the aim of developing methods to mitigate vibration for helicopter aircrew.

Although a performance and health issue, high or low frequency vibration may also be utilized in many military environments to enhance performance. Haptic 
cueing is incorporated into several aviation and naval vehicular environments for orientation cueing, as well as for aircraft collision avoidance and stall warning systems. Haptic systems are gradually being introduced in land environments for group/individual position location and incoming fire warnings (Coerman 1940; Griffin 1990; Guignard and King 1972).

There is no evidence that exposure to vibration leads to significant and permanent behavioral changes or cognitive impairments. However, vibration in the cockpit may negatively impact aircrew performance by interfering with communication, cause a distraction serious enough to cause pain, nausea, and visual decrements, ultimately leading to poor decision-making during routine and emergency operations. This would be exacerbated during long-duration missions.

\section{Acceleration and the Tactical Air Environment}

Acceleration stress continues to be a significant operational hazard for aircrew. Initially recognized as more capable aircraft were developed around World War I, increased thrust and airframe structural strength allowed for aggressive aerial maneuvers, which became operational standards during air-to-air combat and for deployment of munitions (Burton 1988; Lyons et al. 1991). With the introduction of jet propulsion after World War II, these capabilities increased significantly, allowing 8-10 times gravitational forces (commonly termed " $G$ " - which on earth is the force due to gravity acting on the body and is equal to $+1 \mathrm{G}$ ). However, accompanying these increased flight capabilities were numerous loss of consciousness incidents and fatalities among air force personnel across many adversaries' and allies' nations (Ernsting 1966; Burton 1986; Lyons et al. 1991).

Acceleration stress that threatens aircrew health follows the vertical (" $\mathrm{z}$ " or spinal) axis of the body, referred to as "headward acceleration" +Gz. Other vectors of G acceleration are found in the " $\mathrm{x}$ " and " $y$ " directions, especially in other flight or transport environments, but they are usually not associated with significant cardiovascular threats in the tactical aviation environment (Ernsting 1966; Burton 1986; Leverett and Whinnery 1985).

+ Gz causes a perceived "heaviness" of limbs above $+5 \mathrm{Gz}$, with an inability to use or raise the limbs above $+8 \mathrm{Gz}$. Additionally, acceleration acts on the soft tissue and muscles that insert on the spine, and exacerbates the stress imposed by heavy helmet, mask, and sighting equipment. Fatigue of the voluntary respiratory muscles responsible for chest expansion during inspiration is also a feature of high $+\mathrm{Gz}$ levels. One unusual effect of high $+\mathrm{Gz}$ exposure is the development of petechial hemorrhages in the skin - pinpoint type rashes, caused by high hydrostatic tissue pressure. These are usually painless, harmless, and self-limiting to the first few high $+\mathrm{Gz}$ occurrences (Ernsting 1966; Burton 1986).

Blood flow in the upper half of the lungs ceases above $+3 \mathrm{Gz}$, which causes imbalances of oxygen ventilation vs. blood perfusion of the lung. Therefore, there will be a larger volume of perfused lung not receiving oxygen. This results in desaturation of systemic arterial blood such that at $+5 \mathrm{Gz}$, arterial saturation is $85 \%$ (normal is 98\%) (Green 2016). 
As $+\mathrm{Gz}$ acceleration is experienced in the cockpit, several physical/physiological events occur in the immediate seconds of $+\mathrm{Gz}$ stress, the weight of the blood above the heart increases directly as a function of each increment of $+\mathrm{Gz}$; that is, if the aircraft pulls a $+3 \mathrm{Gz}$ turn, the weight of blood in major arteries above the heart increases threefold (Leverett and Whinnery 1985; Burton 1988).

If the $+\mathrm{Gz}$ forces persist for less than 5-7 s, the cardiorespiratory implications to the aircrew are minimal. This is explained by the latent stores of high energy molecules in the brain that enable continued cognition and central nervous system (brain, vision) function for this short time frame. However, if acceleration is sustained longer than 5-7 s and is above $+4-5 \mathrm{Gz}$, oxygen delivery to the central nervous system may be completely interrupted due to low cerebral arterial blood pressure (Green 2016; Burton 1986; Banks et al. 2008; Wood and Lambert 1946).

There are underlying autonomic physiological reflexes that function to restore blood pressure in the face of orthostatic challenges. The most common example is standing too quickly from a supine position, leading to fading vision or fainting (loss of consciousness (LOC)). In the high $+\mathrm{Gz}$ environment, these sympathetic nervous system reflexes are too slow (requiring 7-12 s) and ineffective in the face of high sustained rapid-onset $+\mathrm{Gz}$. Figure 4 illustrates the intersection between natural cardiovascular reflexes and G-onset and symptoms through the "G-Time Tolerance Curve" (Green 2016; Burton 1986; Banks et al. 2008).

The first major effect of increasing $+\mathrm{Gz}$ is an alteration in vision. As head-level arterial pressure decreases with increasing $+\mathrm{Gz}$, blood pressure to the retina falls, and the aircrew will first experience color acuity loss, followed by loss of peripheral vision, and then complete loss of vision. In rapid-onset $+\mathrm{Gz}$, loss of vision may occur simultaneously with LOC. Aircrew are trained (in flight or in centrifuges) to recognize the signs of loss of vision effects, and initiate countermeasures (discussed below), before complete loss of vision or LOC occurs (Green 2016; Burton 1986; Scott et al. 2007; Burns 1988). Aircrew undergoing $+\mathrm{Gz}$ stress may experience changes in behavior, especially after a near-LOC or complete GLOC incident. These may manifest immediately as consciousness returns, and characterized by lethargy, confusion, and apathy (Ernsting 1966; Burton 1986). There is concern that performing complex tasks after GLOC (e.g., conducting an instrument landing in poor weather conditions) may be degraded. Fortunately, there is no evidence that repeated $+\mathrm{Gz}$ insults contribute to permanent changes in behavior or cognition. Certainly, aircrew who experience GLOC may require psychological counseling, as the total loss of control of the aircraft and specter of a possible fatal event may cause anxiety and a range of psychological issues.

The four main factors that govern $+\mathrm{Gz}$ tolerance are the magnitude of $+\mathrm{Gz}$, the rate of onset, the duration of exposure, and the immediate pre-Gz conditions. However, factors such as aircrew morphology (height is known as a risk factor tall individuals being at greater risk), preexisting cardiovascular conditions, medications, diet, sleep, stress, and training are key determinants. Some elements of resilience to $+\mathrm{Gz}$ stress are adaptable and display characteristic adaptive responses with habitual $+\mathrm{Gz}$ exposure, as well as decay in $+\mathrm{Gz}$ tolerance during prolonged layoff from operational flying or centrifuge exposure/training. Additional factors 


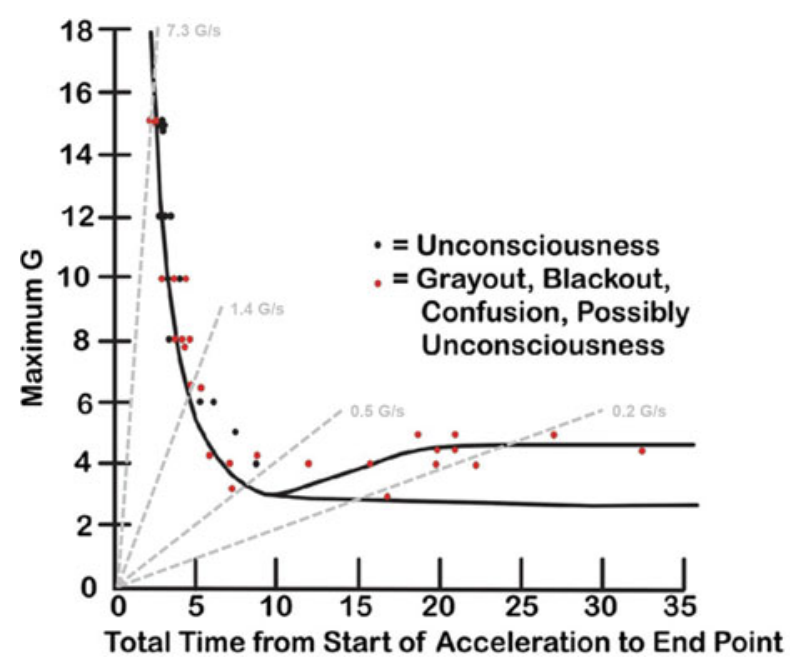

Fig. 4 Maximum $+\mathrm{Gz}$ tolerance versus time from the start of an acceleration in relaxed subjects (i.e., without using a G-protection device or manoeuver) to an endpoint (indicated by the different symbols). Each thin grey line represents acceleration at different onset rates ( $G$ per second, $G / s$ ). With a slower $+\mathrm{Gz}$ onset rate (e.g., $0.2 \mathrm{G} / \mathrm{s}$ ), visual symptoms will occur after $25 \mathrm{~s}$ at $+4 \mathrm{Gz}$ and G-LOC will intervene after $32 \mathrm{~s}$ at $+5 \mathrm{Gz}$. With a gradual onset of $0.5 \mathrm{G} / \mathrm{s}$, visual symptoms are likely after about $8 \mathrm{~s}$ and LOC about $1 \mathrm{~s}$ later at $+4 \mathrm{Gz}$. Rapid onset of sustained $+\mathrm{Gz}(\geq 1.4 \mathrm{G} / \mathrm{s})$ will result in G-LOC after about $4 \mathrm{~s}$ without any visual warning symptoms. However, if rapid-onset $+\mathrm{Gz}$ is sustained for only $1-5 \mathrm{~s}$, there may be no visual disturbances or G-LOC since brain substrate reserves will maintain consciousness. Below the solid black line, the arterial baroreflex effectively counteracts the effect on $+\mathrm{Gz}$, maintaining blood flow to the brain. The exception is if a push-pull maneuver precedes $+\mathrm{Gz}$ (as discussed in the text). (C) Whinnery and Forster. Modified from (Whinnery and Forster 2013) under the terms of the Creative Common Attribution License (http://creativecommons.org/licenses/by/2.0)

influencing $+\mathrm{Gz}$ tolerance are the biodynamics of the flying environment, thermal strain, motion sickness, and vestibular organ stimulation reduces tolerance. Excessive endurance exercise training is also implicated in impaired $+\mathrm{Gz}$ tolerance (Burton 1986).

The simplest countermeasure used in military tactical aviation to mitigate $+\mathrm{Gz}$ exposure has been the reclining of the seat back angle, which diminishes the hydrostatic column height between the heart and the brain (Burns et al. 1975). The most common and effective countermeasure employed by aircrew is the Anti-G Straining Maneuver (AGSM), which effectively raises the $+\mathrm{Gz}$ tolerance threshold from +3.5 or $+4 \mathrm{Gz}$, up to $+8.5-11 \mathrm{Gz}$, depending upon the skill and strength of the aircrew (Wood and Code 1947). The maneuver is a coordinated and cyclic isometric muscle contraction combined with a closed glottis breath hold (Ernsting 1966; Burton 1986; Buick et al. 1992). A well-performed AGSM instantly raises blood pressure and thus retinal and brain perfusion. Though highly effective, it is very fatiguing, especially if used repeatedly during long sorties, and requires extensive aircrew training (usually in human centrifuge facilities). 


\section{Advanced Anti-G suits: expanded air bladders}
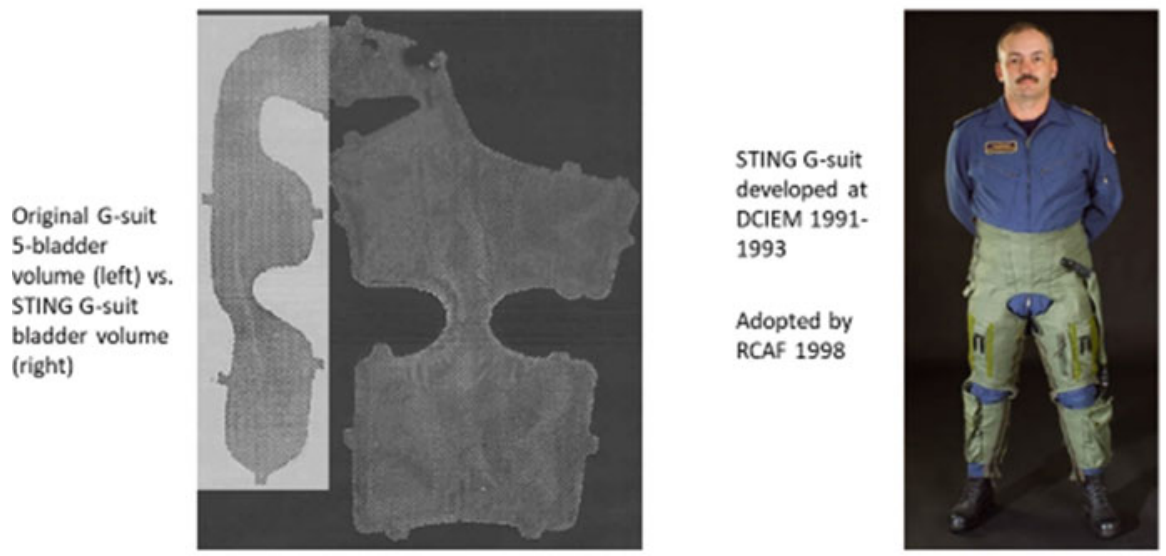

\section{DRDCIRDDC}

Fig. 5 Evolution of the anti-G Suit. Greater bladder volume and lower extremity/abdominal coverage afforded improved protection in combination with the anti-g straining maneuver. Reproduced with permission from the Canadian Department of National Defence. The source is Defence R\&D Canada

Used in tandem with the AGSM is the Anti-G Suit. Invented and developed initially by Canadian and American physiologists during the early World War II period, the first garments used water-filled designs, which exploited the counterpressure created by the increasing pressure of water on the limbs and abdomen during increased $+\mathrm{Gz}$. They were replaced by pneumatic bladders fitted to the inside of the anti-G trousers and a regulator to provide the high-pressure air supply. The basic design (which has remained to this day) is a five-bladder suit: one abdominal, two thigh, and two calf interconnected bladders. The Anti-G suit has undergone several evolutions, and the modern design (e.g., Canada's STING Sustained Tolerance for INcreasing G) anti-G ensemble has larger circumferential bladders, with improved regulators and inflation schedules to optimize + Gz protection (Fig. 5).

Aeromedical scientists recognized during the 1970s and 1980s that PPB (discussed earlier in this chapter) could be exploited for $+\mathrm{Gz}$ protection by partially replacing the respiratory component of the AGSM and passively providing high intrathoracic pressure to the lungs, which is then imparted to the cardiovascular system (Glaister and Lisher 1976). The use of PPB for $+\mathrm{Gz}$ (termed PBG) has the advantage of minimizing AGSM fatigue and allows increased $+\mathrm{Gz}$ exposure tolerance and endurance. Human centrifuge studies demonstrated greater sortie time and $+\mathrm{Gz}$ endurance, reduced fatigue, and reduced chance of GLOC. However, PBG has some limitations: additional aircrew training is required, a thoracic counterpressure vest must be used, the helmet and oronasal mask system is difficult to seal during high $+\mathrm{Gz}$ levels, and a separate regulator is required, complicating the 
life support engineering requirements in the aircraft (Burton 1986; Banks et al. 2008; Scott et al. 2007; Buick et al. 1992; Burns 1988).

\section{Conclusion}

The military operates in extreme environments. Working under varying levels of environmental stress can affect human performance by negatively impacting physical health, psychological health, cognitive functioning, and affecting human behavior. Research on the impact of these environmental stressors on humans, and military members in particular, continues today as in many of these areas of science the understanding of the impact on health and human behavior, including additive stress, continues to evolve.

Research on human performance under these environmental stressors show that in the military context, there are various methods to mitigate some of the impacts. These methods include specialized training, acclimatization, effective monitoring, addition of protective equipment, and behavioral modifications to help reduce the impact of environmental stress on health and human performance. Education and awareness training, such as stress inoculation exposure (Kavanagh 2005), may help soldiers recognize signs of excessive strain and initiate behavioral changes in a manner that helps mitigate against these threats. This type of training can also be beneficial for group performance under stress (Kavanagh 2005). Research about soldiers operating in the heat, for example, has found that physiological monitoring (e.g., heart rate monitoring) can be used in training to help soldiers identify when they are at risk for an injury and encourage behavior changes to reduce the chance of injury and maintain high levels human performance. As biomedical and wearable technologies continue to improve (both sensors and batteries), the adoption of unobtrusive and reliable personal bio-sensors and associated mobile software/algorithms will become feasible for operational use. These systems will be used either as training tools to educate individual performance or to monitor personnel under stress for medical professionals or commanding officers.

As advances in equipment and technology allow humans to push more physical boundaries (e.g., fly faster and climb higher) the military will be exploiting these advances to increase warfighters' advantages over adversaries in environments with extreme stressors. However, having the equipment is only one component of a broader concept of readiness that leadership needs to keep in mind when preparing for operations. Understanding the impact that these environments will have on performance, even with the best equipment, requires a clear realization of how appropriate training and effective leadership contributes to a system of enablers for effectiveness in operating environments that will continue to become increasingly extreme. 


\section{Summary}

This chapter highlights the effects of several operational environments on military personnel during training and operations. Exposure to extremes of noise, temperature, humidity, pressure, vibration, and acceleration can have detrimental effects on physical and cognitive performance and exacerbate psychological stress. These environmental stressors can occur in isolation, such as exposure to extreme cold weather in the Arctic, or they can be additive, such as experiencing noise, vibration, and acceleration in aircraft. Environmental stress can also affect human behavior, and it is important to understand how adaptations or behavior changes can impact military operations and mission effectiveness. Education and training, appropriate use of protective clothing, leadership, technology, and experience all play a role in learning how to mitigate the risk of environmental injuries and degraded performance in these extreme environments. Research on human performance under these environmental stressors in the military context explores ways to mitigate the harmful effects of environmental stress and augment warfighters' ability to operate in extreme environments.

\section{Cross-References}

Air Operations

- Land Operations

- Maybe These or Nothing

What is Military Operations?

What is Military Sciences?

\section{References}

Ackles, K. N., Porlier, J. A., Holness, D. E., Wright, G. R., Lambert, J. M., \& McArthur, W. J. (1978). Protection against the physiological effects of positive pressure breathing. Aviation, Space, and Environmental Medicine, 49(6), 753-758.

Ashworth, E. T., Cotter, J. D., \& Kilding, A. E. (2020). Methods for improving thermal tolerance in military personnel prior to deployment. Military Medical Research, 7(1), 58.

Balldin, U. I. (1978). Explosive decompression of subjects up to a 20,000-m altitude using a two-pressure flying suit. Aviation, Space, and Environmental Medicine, 49(4), 599-602.

Banks, R. D., Brinkley, J. W., Allnutt, R., \& Harding, R. M. (2008). Human response to acceleration. In J. R. Davis, R. Johnson, J. Stepanek, \& J. A. Fogarty (Eds.), Fundamentals of aerospace medicine (4th ed., pp. 83-109). Philadelphia: Lippincott Williams \& Wilkins.

Bert, P. (1878). La pression barométrique: Recherches de physiologie expérimentale (G. Masson, Ed.). Paris: Libraire de l'Académie de Medicine. [Barometric pressure: Researches in experimental physiology. Columbus: College Book Company. Translated to English by: Hitchcock, M. A.; Hitchcock, F. A in 1943].

Bricknell, M. (1995). Heat illness - A review of military experience (part 1). Journal of the Royal Army Medical Corps, 141(3), 157-166. 
Buick, F., Hartley, J., \& Pecaric, M. (1992). Maximum intra-thoracic pressure with anti-G straining maneuvers and positive pressure breathing during $+\mathrm{Gz}$. Aviation, Space, and Environmental Medicine, 63(8), 670-677.

Burns, J. W. (1988). Prevention of loss of consciousness with positive pressure breathing and supinating seat. Aviation, Space, and Environmental Medicine, 59(1), 20-22.

Burns, J. W., Iampietro, P. F., \& Leverett, S. D. (1975). Physiologic effects of seatback angles $<45$ degrees (from the vertical) relative to G. Aviation, Space, and Environmental Medicine, 46(7), 887-897.

Burton, R. R. (1986). A conceptual model for predicting pilot group $\mathrm{G}$ tolerance for tactical fighter aircraft. Aviation, Space, and Environmental Medicine, 57(8), 733-744.

Burton, R. R. (1988). G-induced loss of consciousness: Definition, history, current status. Aviation, Space, and Environmental Medicine, 59(1), 2-5.

Candler, W. H. (1997). Cold weather injuries among U.S. soldiers in Alaska: A five-year review. Military Medicine, 162(12), 788-791.

Carlyle, L. (1963). High altitude breathing. Approach, 8(7), 30-35.

Carson, R. P., Evans, W. O., Shields, J. L., \& Hannon, J. P. (1969). Symptomatology, pathophysiology, and treatment of acute mountain sickness. Federation Proceedings, 28(3), 1085-1091.

Castellani, J. W., Yurkevicius, B. R., Jones, M. L., Driscoll, T. J., Cowell, C. M., Smith, L., Xu, X., \& O'Brien, C. (2018). Effect of localized microclimate heating on peripheral skin temperatures and manual dexterity during cold exposure. Journal of Applied Physiology (Bethesda, Md.: 1985), 125(5), 1498-1510.

Cheung, S. S. (2015). Responses of the hands and feet to cold exposure. Temperature (Austin, Tex.), 2(1), 105-120.

Coerman, R. (1940). Investigations into the effect of vibration on the human body (Library Translation No. 217). London. Ministry of Defence.

Crandall, C. G., Rickards, C. A., \& Johnson, B. D. (2019). Impact of environmental stressors on tolerance to hemorrhage in humans. American Journal of Physiology - Regulatory, Integrative and Comparative Physiology, 316(2), R88-R100.

Cudaback, D. D. (1984). 4-KM altitude effects on performance and health. Publications of the Astronomical Society of the Pacific, 96(580), 463-477.

DeHart, R. L. (1996). The historical perspective. In R. L. DeHart (Ed.), Fundamentals of aerospace medicine (2nd ed.). Baltimore: Williams \& Wilkins.

Department of the Army (2005). Technical Bulletin Medical (TB MED) 508: Prevention and management of cold-weather injuries. Washington, D.C.: Headquarters, Department of the Army.

Ernsting, J. (1966). Some effects of raised intrapulmonary pressure in man (AGARDOgraph 106). London: W. and J. Mackay.

Ernsting, J., Green, I. D., Nagle, R. E., \& Wagner, P. R. (1960). High altitude protection from pressure-breathing mask with trunk and lower limb counterpressure. Aerospace Medicine, 31, $40-48$.

Glaister, D. H., \& Lisher, B. J. (1976). Pressure breathing as a means of enhancing tolerance to sustained positive accelerations. In Proceedings of a Symposium on Biomedical and Biophysical Aspects of Oxygen Systems, 17th Meeting of Air Standardization Coordinating Committee. (Working Party 61, pp. 138-144). Farnborough.

Goines, L., \& Hagler, L. (2007). Noise pollution: A modern plague. Southern Medical Journal, $100(3), 287-294$.

Goldman, R. F. (2001). Introduction to heat-related problems in military operations. In K. B. Pandolf \& R. E. Burr (Eds.), Medical aspects of harsh environments (Vol. 1, pp. 3-49). Washington, D.C.: Borden Institute, Walter Reed Army Medical Center.

Goodman, L. S., Fraser, W. D., Ackles, K. N., Mohn, D., \& Pecaric, M. (1993). Effect of extending G-suit coverage on cardiovascular responses to positive pressure breathing. Aviation, Space, and Environmental Medicine, 64(12), 1101-1107. 
Gordon, K., Blondin, D. P., Friesen, B. J., Tingelstad, H. C., Kenny, G. P., \& Haman, F. (2019). Seven days of cold acclimation substantially reduces shivering intensity and increases nonshivering thermogenesis in adult humans. Journal of Applied Physiology (Bethesda, Md.: 1985), 126(6), 1598-1606.

Gorjanc, J., Morrison, S. A., McDonnell, A. C., Mekjavic, P. J., Blagus, R., \& Mekjavic, I. B. (2019). Ski-Everest (8848 m) expedition: Digit skin temperature responses to cold immersion may reflect susceptibility to cold injury. Wilderness \& Environmental Medicine, 30(2), 141-149.

Green, N. (2016). Long duration acceleration. In D. Gradwell \& D. P. Rainford (Eds.), Ernsting's aviation and space medicine (5th ed., pp. 131-156). London: CRC Press.

Greene, R. (1957). Mental performance in chronic anoxia. British Medical Journal, 1(5026), $1028-1031$.

Griffin, M. J. (1990). Handbook of human vibration. London: Academic Press.

Guignard, J. C., \& King, P. F. (1972). Aeromedical aspects of vibration and noise (AGARDOgraph AG-151). Neuilly-sur-Seine, France: AGARD/NATO.

Haldane, J. S., Kellas, A. M., \& Kennaway, E. L. (1919). Experiments on acclimatisation to reduced atmospheric pressure. Journal of Physiology, 53(3-4), 181-206.

Handford, C., Buxton, P., Russell, K., Imray, C. E., McIntosh, S. E., Freer, L., Cochran, A., \& Imray, C. H. (2014). Frostbite: A practical approach to hospital management. Extreme Physiology \& Medicine, 3, 7.

Harding, R. M., \& Gradwell, D. P. (1999). Hypoxia and hyperventilation. In J. Ernsting, A. N. Nicholson, \& D. J. Rainford (Eds.), Aviation medicine (pp. 43-58). Oxford: ButterworthHeinemann.

Hitchcock, F. A. (1971). Paul Bert and the beginnings of aviation medicine. Aerospace Medicine, 42(10), 1101-1107.

Holness, D. E., Porlier, J. A., Ackles, K. N., \& Wright, G. R. (1980). Respiratory gas exchange during positive pressure breathing and rapid decompression to simulated altitudes of 18.3 and $24.4 \mathrm{~km}$. Aviation, Space, and Environmental Medicine, 51(5), 454-458.

Houston, C. S. (1987). Going higher, the story of man and altitude. Boston: Little Brown and Company.

Jacobs, I., Michas, R., Limmer, R., Kerrigan-Brown, D., \& McLellan, T. (2007). Heat stress mitigation for Leopard 2C tank crew. Defence Research and Development Canada TR 2007082, 1-34.

Jarcho, S. (1967). A Roman experience with heat stroke in 24 B.C. Bulletin of the New York Academy of Medicine, 43(8), 767-768.

Jokel, C., Yankaskas, K., \& Robinette, M. B. (2019). Noise of military weapons, ground vehicles, planes and ships. The Journal of the Acoustical Society of America, 146(5), 3832.

Jones, D. M., Bailey, S. P., Roelands, B., Buono, M. J., \& Meeusen, R. (2017). Cold acclimation and cognitive performance: A review. Autonomic Neuroscience: Basic \& Clinical, 208, 36-42.

Kavanagh, J. (2005). Stress and performance: A review of the literature and its applicability to the military. Santa Monica: RAND Corporation.

Keller, M. D., Ziriax, J. M., Barns, W., Sheffield, B., Brungart, D., Thomas, T., Jaeger, B., \& Yankaskas, K. (2017). Performance in noise: Impact of reduced speech intelligibility on Sailor performance in a Navy command and control environment. Hearing Research, 349, 55-66.

Kenefick, R. W., Cheuvront, S. N., Castellani, J. W., \& O’Brien, C. (2008). Thermal stress. In J. R. Davis, R. Johnson, J. Stepanek, \& J. A. Fogarty (Eds.), Fundamentals of aerospace medicine (4th ed., pp. 206-220). Philadelphia: Lippincott Williams \& Wilkins.

Kozlowski, F. (2009). U.S. Marines in battle: An-Najaf. Washington, DC: United States Marine Corps History Division.

Lazarus, R. S., \& Cohen, J. B. (1977). Environmental stress. In I. Altman \& J. F. Wohlwill (Eds.), Human behavior and environment. Boston: Springer. https://doi.org/10.1007/978-1-46840808-9 3 . 
Leverett, S. D., \& Whinnery, J. E. (1985). Biodynamics: Sustained acceleration. In R.L. Dehart (Ed.), Fundamentals of aerospace medicine (1st ed., pp. 122-153). Philadelphia: Lea and Febiger.

Lloyd, A., \& Havenith, G. (2016). Interactions in human performance: An individual and combined stressors approach. Temperature (Austin, Tex.), 3(4), 514-517.

Lyons, T. J., Harding, R., Freeman, J., \& Oakley, C. (1991, April). G-induced loss of consciousness accidents USAF experience 1982-1990. In High altitude and high acceleration protection for military aircrew (AGARD Conference Proceedings 516, pp. 51-55). Nueilly-sur-Seine: AGARD/NATO.

Malle, C., Quinette, P., Laisney, M., Bourrilhon, C., Boissin, J., Desgranges, B., Eustache, F., \& Piérard, C. (2013). Working memory impairment in pilots exposed to acute hypobaric hypoxia. Aviation, Space, and Environmental Medicine, 84(8), 773-779.

Marotte, H. (2006). [The exposure of man to altitude when flying: From Paul Bert to today] [Original article in French]. Journal de la Société de biologie, 200(3):251-255.

Martin, K., McLeod, E., Periard, J., Rattray, B., Keegan, R., \& Pyne, D. B. (2019). The impact of environmental stress on cognitive performance: A systematic review. Human Factors, 61(8), $1205-1246$.

McLellan, T. M., Daanen, H. A. M., \& Cheung, S. S. (2013). Encapsulated environment. Comprehensive Physiology, 3(3), 1363-1391.

Münzel, T., Sørensen, M., Schmidt, F., Schmidt, E., Steven, S., Kröller-Schön, S., \& Daiber, A. (2018). The adverse effects of environmental noise exposure on oxidative stress and cardiovascular risk. Antioxidants \& Redox Signaling, 28(9), 873-908.

Nakashima, A., \& Farinaccio, R. (2015). Review of weapon noise measurement and damage risk criteria: Considerations for auditory protection and performance. Military Medicine, 180(4), 402-408.

Nindl, B. C., Billing, D. C., Drain, J. R., Beckner, M. E., Greeves, J., Groeller, H., Teien, H. K., Marcora, S., Moffitt, A., Reilly, T., Taylor, N. A. S., Young, A. J., \& Friedl, K. E. (2018). Perspectives on resilience for military readiness and preparedness: Report of an international military physiology roundtable. Journal of Science and Medicine in Sport, 21(11), 1116-1124.

Nunneley, S. A., \& Stribley, R. F. (1979). Heat and acute dehydration effects on acceleration response in man. Journal of Applied Physiology: Respiratory, Environmental and Exercise Physiology, 47(1), 197-200.

Nye, N. S., \& O'Connor, F. G. (2020). Exertional heat illness considerations in the military. In W. M. Adams \& J. Jardine (Eds.), Exertional heat illness: A clinical and evidence-based guide (pp. 181-209). Switzerland: Springer International Publishing.

Olsen, E. W. (1997). The Battle of Hattin, 1187 (Master's Thesis). U.S. Army Command and General Staff College.

Petrassi, F. A., Hodkinson, P. D., Walters, P. L., \& Gaydos, S. J. (2012). Hypoxic hypoxia at moderate altitudes: Review of the state of the science. Aviation, Space, and Environmental Medicine, 83(10), 975-984.

Rice, G. M., Snider, D., Drollinger, S., Greil, C., Bogni, F., Phillips, J., Raj, A., Marco, K., \& Linnville, S. (2019). Dry-EEG manifestations of acute and insidious hypoxia during simulated flight. Aerospace Medicine and Human Performance, 90(2), 92-100.

Schiefer, R. E., Kok, R., Lewis, M. I., \& Meese, G. B. (1984). Finger skin temperature and manual dexterity-some intergroup differences. Applied Ergonomics, 15(2), 135-141. https://doi.org/10. 1016/0003-6870(84)90291-6

Schlader, Z. J., Gagnon, D., Adams, A., Rivas, E., Cullum, C. M. \& Crandall, C. G. (2015). Cognitive and perceptual responses during passive heat stress in younger and older adults. American Journal of Physiology. Regulator, Integrative and Comparitive Physiology, 308(10), R847-854. https://doi.org/10.1152/ajpregu.00010.2015

Scott, J. M., Esch, B. T. A., Goodman, L. S., Bredin, S. S. D., Haykowsky, M. J., \& Warburton, D. E. R. (2007). Cardiovascular consequences of high-performance aircraft maneuvers: 
Implications for effective countermeasures and laboratory-based simulations. Applied Physiology, Nutrition, and Metabolism, 32(2), 332-339. https://doi.org/10.1139/h06-087

Smith, A. M. (2008). Hypoxia symptoms in military aircrew: long-term recall vs. acute experience in training. Aviat Space Environ Med, 79, 54-57.

Sullivan-Kwantes, W., Dhillon, P., Goodman, L., \& Knapik, J. J. (2017). Medical encounters during a joint Canadian/U.S. exercise in the high Arctic (Exercise Arctic Ram). Military Medicine, 182 (9), e1764-e1768. https://doi.org/10.7205/MILMED-D-16-00390

Taylor, L., Watkins, S. L., Marshall, H., Dascombe, B. J., \& Foster, J. (2016). The impact of different environmental conditions on cognitive function: A focused review. Frontiers in Physiology, 6, 372. https://doi.org/10.3389/fphys.2015.00372

Tiwari, G. K. (2011). Stress and human performance. Indo-Indian Journal of Social Science Researches, 7(1), 40-49.

Vale, T. A., Symmonds, M., Polydefkis, M., Byrnes, K., Rice, A. S. C., Themistocleous, A. C., \& Bennett, D. L. H. (2017). Chronic non-freezing cold injury results in neuropathic pain due to a sensory neuropathy. Brain: A Journal of Neurology, 140(10), 2557-2569.

West, J. B. (1998). High life. A history of high-altitude physiology and medicine. New York/Oxford: Oxford University Press.

Whinnery, T., \& Forster, E. M. (2013). The + Gz-induced loss of consciousness curve. Extreme Physiology and Medicine, 2(1), 19.

Wood, E. H., \& Code, C. F. (1947). The physiological basis of voluntary (self-protective) maneuvers capable of increasing man's tolerance to positive acceleration. In 17th International Physiologist Congress Proceedings (pp. 311-312).

Wood, E. H., \& Lambert, E. H. (1946). The effect of anti-blackout suits on blood pressure changes produced on the human centrifuge (Vol. 4, pp. 115-116). Fed Pro.

Yong, J. S., \& Wang, D. Y. (2015). Impact of noise on hearing in the military. Military Medical Research, 2, 6 .

\section{Further Reading}

\section{Noise}

NATO RTO. (2010). Hearing protection: needs, technologies and performance (AC/323 (HFM-147)TP/337). Neuilly-sur-Seine: NATO.

\section{Cold}

Fox, W. F. (1967). Human performance in the cold. Human Factors, 9(3), 203-220.

Imray, C. H. E., \& Oakley, E. H. N. (2005). Cold still kills: Cold-related illnesses in military practice freezing and non-freezing cold injury. Journal of the Royal Army Medical Corps, 151(4), 218-222. 
Sullivan-Kwantes, W., Haman, F., Kingma. B. R. M., Martini, S., Gautier-Wong, E., Chen, K. Y., \& Friedl, K. E. (2020). Human performance research for military operations in extreme cold environments. Journal of Science and Medicine in Sport, 24(10), 954-962.

\section{Heat}

Pandolf, K. B., \& Burr, R. E. (Eds.). (2001-2). Medical aspects of harsh environments (Vol. 1-2). Washington, D.C.: Borden Institute, Walter Reed Army Medical Center.

\section{Hypoxia}

DeHart, R. L. (Ed.). (1996). Fundamentals of aerospace medicine. Baltimore: Williams \& Wilkins. Fulco, C. S., \& Cymerman, A. (1988). Human performance and acute hypoxia. In K. B. Pandolf, M. N. Sawka, \& R. R. Gonzales (Eds.), Human performance physiology and environmental medicine at terrestrial extremes (pp. 467-495). Indianapolis: Cooper Publishing Group.

\section{Vibration}

Ernsting, J. (1961). Respiratory effect on whole-body vibration (RAF Institute of Aviation Medicine Report No. 1790). London: Ministry of Defence.

Magid, E. R., Coerman, R. R., \& Ziegenruecker, G. M. (1960). Human tolerance to whole-body sinusoidal vibration. Short-time, one-minute and three-minute studies. Aerospace Medicine, 31, 915-924.

Rollin-Stott, J. R. (2016). Vibration. In D. Gradwell \& D. Rainford (Eds.), Ernsting's aviation and space medicine (5th ed., pp. 213-228). Boca Raton: CRC Press.

\section{Acceleration and the Tactical Environment}

AMP Working Group 14. (1990). High G physiological protection training (AGARDograph No. 322). Neuilly-sur-Seine: AGARD/NATO.

Banks, R. D., Grisset, J. D., Turnspeed, G. T., Saunders, P. L., \& Rupert, A. H. (1994). The pushpull effect. Aviation, Space, and Environmental Medicine, 65(8), 699-704. 
Goodman, L., \& LeSage, S. (2002). Impairment of cardiovascular and vasomotor responses during 'push-pull' maneuvers. Aviation, Space, and Environmental Medicine, 73(10), 971-979.

High Altitude and High Acceleration Protection for Military Aircrew. AGARD Conference Proceedings 516 April 1991. NATO Nueilly Sur Seine, France.

Howard, P. (1965). The physiology of positive acceleration. In J. A. Gilles (Ed.), A textbook of aviation physiology (pp. 551-687). Oxford/London: Pergamon Press.

Wood, E. H., Lambert, E. H., Baldes, E. J., \& Code, C. F. (1946). Effects of acceleration in relation to aviation. Federation Proceedings, 5, 327-344.

Open Access This chapter is licensed under the terms of the Creative Commons Attribution 4.0 International License (http://creativecommons.org/licenses/by/4.0/), which permits use, sharing, adaptation, distribution and reproduction in any medium or format, as long as you give appropriate credit to the original author(s) and the source, provide a link to the Creative Commons license and indicate if changes were made.

The images or other third party material in this chapter are included in the chapter's Creative Commons license, unless indicated otherwise in a credit line to the material. If material is not included in the chapter's Creative Commons license and your intended use is not permitted by statutory regulation or exceeds the permitted use, you will need to obtain permission directly from the copyright holder.

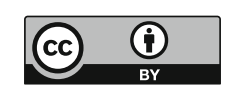

